\title{
PERFIL E PERCEPÇÃO AMBIENTAL DE FREQUENTADORES DO PARQUE DO GUARAPIRANGA - SÃO PAULO/SP
}

Profile and environmental perception of frequenters the park Guarapiranga - São

$$
\text { Paulo/SP }
$$

Perfil y perceptíon ambiental de frecuentadores parque Guarapiranga - São Paulo/SP

Edmilson Nazareno Brito Mestrando, GeAS - UNINOVE, Brasil edmilsonbrito@hotmail.com

Milena de Moura Régis Professora Mestre, UNINOVE, Brasil milenaregis@hotmail.com

Ana Paula do Nascimento Lamano-Ferreira Professora Doutora, GeAS-UNINOVE, Brasil apbnasci@yahoo.com.br 
O estudo sobre a percepção ambiental é de fundamental importância para compreender melhor as inter-relações entre o homem e o ambiente, suas expectativas, anseios, satisfações, julgamentos e condutas. Portanto, o presente estudo foi realizado para se analisar a percepção ambiental de frequentadores de um parque urbano, e desta forma obter dados que possam auxiliar gestores e responsáveis pela infraestrutura presente no parque, em projetos e programas atuais e futuros além da educação ambiental. $O$ estudo foi desenvolvido no Parque do Guarapiranga localizado na região Sul da Cidade de São Paulo, local onde há uma carência de áreas verdes e espaços de lazer. Para o levantamento de dados, foram entrevistados 30 frequentadores do Parque por meio de um questionário semiestruturado. Por meio das respostas observou-se a percepção dos respondentes tem relação ao espaço e as pessoas, a existência de conflitos sobre o uso e os cuidados do espaço do parque e as necessidades reivindicadas por seus usuários. $O$ estudo pode desta forma auxiliar na tomada de decisões dos gestores do parque para melhorar o atendimento as necessidades e anseios que a população frequentadora possui.

Palavras Chaves: Percepção Ambiental; Áreas Verdes Urbanas; Planejamento Urbano

\section{ABSTRACT}

The study on environmental perception is crucial to better understand the interrelationships between man and the environment, their expectations, desires, satisfactions, judgments and behaviors. Therefore, this study has been conducted to analyze the environmental perception of frequenters in an urban park, and thus obtain data that can assist managers and those responsible for this infrastructure in the park, on projects and current and future programs as well as environmental education. The study was developed in the Guarapiranga Park located in the southern region of the city of São Paulo, where there is a lack of green areas and recreational areas. For the survey data, were interviewed 30 frequenters Park by a semi-structured questionnaire. By the responses observed the perception of respondents relates to space and people, the existence of conflicts over the use and care of park space and they claimed needs for its members. The study can thus help in the making of park managers to improve customer service needs and desires that the population has frequenter.

Keywords: environmental perception; Urban Green Areas; Urban Planning.

\section{RESUMEN}

El estudio sobre la percepción ambiental es crucial para entender mejor las relaciones entre el hombre y el medio ambiente, sus expectativas, deseos, satisfacciones, juicios y comportamientos.El estudio se realizó para analizar la percepción del medio ambiente frecuentadores de un parque urbano, y por lo tanto obtener datos que pueden ayudar a los administradores y los responsables de la infraestructura en el parque, en los proyectos y programas actuales y futuros, así como en la educación ambiental. El estudio fue desarrollado en el Parque Guarapiranga situado en la región sur de la ciudad de Sao Paulo, donde hay una falta de áreas verdes y zonas de recreo. Para los datos de la encuesta, se entrevistó a 30 asistentes del parque a través de un cuestionario semi-estructurado. A través de las respuestas observadas de la percepción de los encuestados se relaciona con el espacio y las personas, la existencia de conflictos sobre el uso y cuidado del espacio del parque y las necesidades reclamadas por sus miembros. El estudio puede así ayudar en la elaboración de los encargados del parque para mejorar las necesidades de servicio al cliente y deseos que la población frecuentadora tiene."

Palablas claves: percepción ambiental, áreas verdes urbanas, Urbanismo. 


\section{INTRODUÇÃO}

Há uma crescente preocupação com as questões ambientais e qualidade de vida das pessoas que vivem nos centros urbanos. Tais preocupações já eram apontadas nas diversas conferências mundiais sobre o meio ambiente organizadas pela ONU (Organização das Nações Unidas) como a que ocorreu no Rio de Janeiro em 1992 (ECO-92).

A maioria dos organismos internacionais estão preocupados com a preservação e conservação dos grandes ecossistemas, dando menor importância a áreas verdes de pequena escala em cidades perto de onde as pessoas vivem e trabalham, porém há uma percepção entre os moradores de grandes centros urbanos que estas áreas contribuem para a qualidade de vida de muitas maneiras (CHIESURA, 2004).

Os parques urbanos fornecem benefícios ambientais e ecológicos, sociais e psicológicos importantes para as sociedades humanas enriquecendo a vida humana com significados e emoções (CHIESURA,2004).

Os habitantes dos grandes centros urbanos procuram as áreas verdes para vários fins como lazer, contato com a natureza, meditação, prática de esportes etc. É importante que a população tenha conhecimento e valorização destas áreas. Este é um fator importante para a sua conservação (VIANNA ET AL, 2014).

Com a criação da Lei n. 9.985 em 2000, o parque urbano no Brasil assume novo significado e função: preservação da biodiversidade para o bem coletivo. $O$ parque urbano passa a ser 0 lócus da preservação ambiental, da contemplação e do bem-estar daqueles que o utilizam e/ou que vivem ao redor do parque (CARDOSO, VASCONCELOS SOBRINHO \& VASCONCELLOS, 2015).

O município de São Paulo é uma cidade de crescimento rápido desordenado, carente de áreas verdes. Apesar de ter sofrido intensa transformação no uso de solo, ainda possuí áreas florestais nativas, vários parques municipais e áreas particulares possuem essas áreas (GARCIA e PIRANI, 2001). Os parques urbanos são vistos como locais de preservação dos resquícios de áreas verdes existentes nas grandes cidades. (RÉGIS, 2016).

Desde 2005 cidade de São Paulo, de acordo com as propostas da Rio/1992, procura desenvolvimento sustentável em seu planejamento urbano. A Prefeitura desenvolve vários projetos com objetivo de melhorar e aumentar as áreas verdes da cidade, por exemplo orientando os munícipes a plantar árvores em espaços adequados (BARBEDO, 2005). Um dos projetos desenvolvidos foi intitulado "100 Parques para São Paulo" que almejava a a inauguração do centésimo parque na cidade, objetivo alcançado em dezembro de 2012.

O estudo sobre a cognição e percepção é de fundamental importância para que possamos compreender melhor as inter-relações entre o homem e o ambiente, suas expectativas, anseios, satisfações, julgamentos e condutas. (TUAN, 2012).

Uma das dificuldades para a proteção dos ambientes naturais está na existência de diferenças nas percepções dos valores e da importância dos mesmos entre os indivíduos de culturas 


\section{ANAP

diferentes ou de grupos socioeconômicos que desempenham funções distintas, no plano social, nesses ambientes.

Nesse sentido, os conhecimentos sobre os parques de São Paulo oferecem a cidade a oportunidade de melhorar a sua qualidade ambiental, proporcionando para os habitantes sensação de conforto e bem-estar.

Para tanto é necessário ter conhecimento de como seus habitantes percebem o ambiente, estudos da percepção ambiental ajudam a enfrentar os desafios de dar resposta as necessidades e anseios da comunidade

Desta forma, o estudo pretende saber qual o perfil e a percepção dos frequentadores sobre o Parque do Guarapiranga localizado na cidade de São Paulo.

\section{OBJETIVO}

- O objetivo deste trabalho foi relatar a percepção ambiental dos frequentadores entrevistados do Parque do Guarapiranga.

\subsection{Objetivos Específicos}

- Discutir sobre as necessidades dos frequentadores do parque;

- Avaliar quais melhorias poderiam ser efetuadas nos parques para atender as necessidades dos seus frequentadores;

- Subsidiar gestores e administradores de parque com informações.

\section{METODOLOGIA}

\section{1 Área de Estudo.}

O Parque do Guarapiranga localiza-se na Estrada do Guarapiranga, 575 no Jardim Alves de lima subprefeitura de M'Boi Mirim bairro de Campo Limpo no município de São Paulo.

A área onde hoje está instalado o Parque Guarapiranga originou-se da desapropriação, entre 1937 e 1938, de quatro lotes contíguos, somando-se 157.922,90m, para a implantação de um do "clube dos meninos" construído na primeira gestão do prefeito Preste Maia. O clube foi desativado em meados de 1960, a partir de então começaram as gestões para o aproveitamento do terreno para a construção de um parque público (BARTALINI, 1999).

O parque do Guarapiranga foi elaborado pelo escritório do paisagista Burle Marx e aberto ao público em 1974. A área pertencente ao parque está inserida dentro da área de proteção dos mananciais. 


\section{ANAP

O parque possui uma área total de $152.600 \mathrm{~m}^{2}$ encontra-se as margens da Represa do Guarapiranga construída em 1908, suas águas foram utilizadas para geração de energia elétrica para a região. A partir de 1928, a represa do Guarapiranga tornou-se a fonte de água para abastecimento público de São Paulo.

As pessoas que frequentam o parque são de todas idades e utilizam o parque principalmente para lazer, esporte e descanso. O parque possui campo de futebol, quadras poliesportivas, trilha, playgrounds, quiosques, churrasqueiras, aparelhos de longevidade. $\mathrm{N}$ área também funcionam CECCO- Centro de Convivência e Cooperativa e Bosque da Leitura. O parque já foi utilizado para banho e natação, porém atualmente a prática é proibida.

A flora do parque é constituída por eucaliptal entremeados por pequenos bosques de Mata Atlântica e espécies exóticas. Sua fauna é rica, sendo encontrados 40 tipos de borboletas, lagarto teiú, gambá e ratão do banhado e cerca de 49 espécies de aves (GPMSP, 2015).

A partir da década de 70 ocorre um grande adensamento populacional na região, núcleos urbanos precários começam a se instalar no território, várias favelas desenvolveram no entorno da represa e do parque (CHAKARIAN, 2008).

Figura 1 - Localização do Parque do Guarapiranga

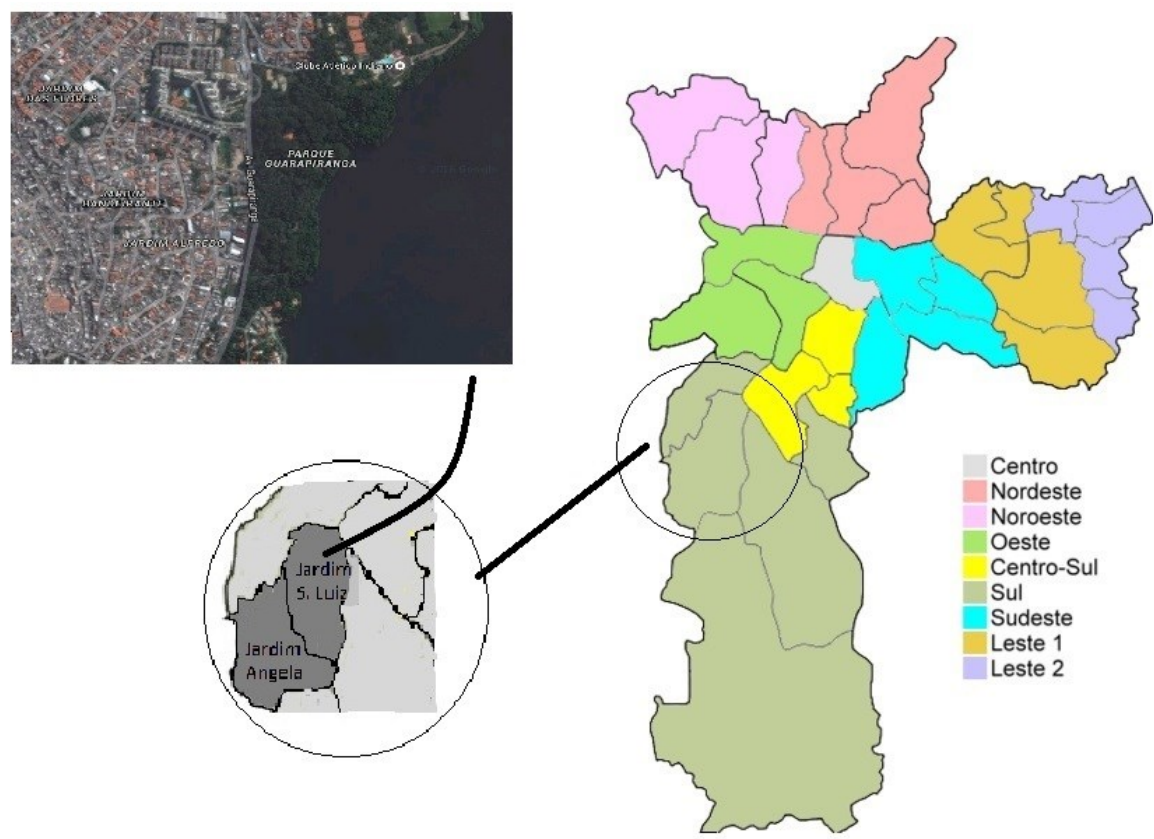

Fonte: Elaborado pelos autores utilizando imagens do Google Maps

\subsection{Coleta de Dados.}




\section{ANAP

Tabela 1. Perfil socioambiental da população estudada no Parque Guarapiranga, região Sul da cidade de São Paulo, SP.

\begin{tabular}{|c|c|c|c|c|}
\hline \multirow{2}{*}{$\begin{array}{ll} & \text { VARIÁVEIS } \\
\text { FAIXA ETÁRIA } & \end{array}$} & \multicolumn{2}{|c|}{ HOMENS } & \multicolumn{2}{|c|}{ MULHERES } \\
\hline & $\mathrm{N}=15$ & $\%$ & $\mathrm{~N}=15$ & $\%$ \\
\hline 19 a 29 anos & 3 & $10 \%$ & 4 & $13 \%$ \\
\hline 30 a 49 anos & 9 & $30 \%$ & 8 & $27 \%$ \\
\hline 50 anos ou mais & 3 & $10 \%$ & 3 & $10 \%$ \\
\hline \multicolumn{5}{|l|}{ NIVEL DE ESCOLARIDADE } \\
\hline Ensino Fundamental incompleto & 3 & $10 \%$ & 3 & $10 \%$ \\
\hline Ensino Médio incompleto & 1 & $3,3 \%$ & 2 & $6,7 \%$ \\
\hline Ensino Médio completo & 5 & $16,6 \%$ & 3 & $10 \%$ \\
\hline Ensino Superior incompleto & - & - & 2 & $6,7 \%$ \\
\hline Ensino Superior Completo & 6 & $20 \%$ & 5 & $16,6 \%$ \\
\hline \multicolumn{5}{|l|}{ ACESSO AO PARQUE } \\
\hline A pé & 7 & 23,3 & 6 & $20 \%$ \\
\hline Ônibus & 3 & $10 \%$ & 6 & $20 \%$ \\
\hline Ônibus e Metro & 1 & $3,3 \%$ & 1 & $3,3 \%$ \\
\hline Carro & 4 & $13,3 \%$ & 2 & $6,7 \%$ \\
\hline \multicolumn{5}{|l|}{ RELAÇÃO COM A NATUREZA } \\
\hline & 1 & $3,3 \%$ & - & \\
\hline & 2 & $6,7 \%$ & 2 & $6,7 \%$ \\
\hline & 2 & $6,7 \%$ & 1 & $3,3 \%$ \\
\hline & 5 & $16,7 \%$ & 6 & $20 \%$ \\
\hline & 5 & $16,7 \%$ & 6 & $20 \%$ \\
\hline
\end{tabular}

Fonte: Elaborado pelos autores a partir dos dados levantados.

A faixa etária mais frequente na pesquisa foi de adultos entre 30 a 49 anos com 57\%, a faixa etária dos mais velhos e mais novos foram respectivamente $20 \%$ e $23 \%$, a faixa etária de menores de 18 anos não foram levantadas, pois as entrevistas somente foram feitas com os indivíduos maiores de 18 anos.

A faixa de escolaridade de maior predominância entre os frequentadores entrevistados foi a de que possuíam nível superior completo $36,60 \%$, a segunda faixa foi a de ensino médio completo com $26,60 \%$, ensino médio incompleto $10 \%$ e a faixa de ensino fundamental incompleto de $20 \%$

Quanto ao acesso, a maioria dos entrevistados acessa o parque a pé $43,3 \%$ seguido daqueles que acessam o parque utilizando ônibus (30\%), os que vão ao parque de carro somaram $20 \%$ e os que utilizam ônibus e metro foram apenas $6,7 \%$. Este resultado indica que os principais frequentadores do parque moram próximos a ele.

$\mathrm{Na}$ entrevista uma das questões apresentava a seguinte questão " Qual a figura descreve sua relação (eu) com a natureza?". 
Observa-se que as respostas mais frequentes são as que aproxima mais a pessoa a natureza $36,7 \%$ e a que a pessoa se encontra ainda dentro da natureza 36,7 , somando-se estas duas categorias se tem um total $73,4 \%$. Aqueles que acham que estão apenas em contato com a natureza mais dissociando-se delas tiveram $10 \%$ e $13,4 \%$ respectivamente, apenas uma pessoa admitiu estar distante da natureza 3,3\%.

As respostas a pergunta "Como você descreveriam o parque alguém que nunca o visitou. " Observou-se a importância dada pelos frequentadores ao parque pelo contato com a natureza, a sensação de tranquilidade; a paisagem; a possibilidade de realizar atividades físicas, principalmente espaço de lazer. As respostas dos entrevistados foram transcritos e são apresentados no Quadro 1.

Quadro 1 - Percepção de frequentadores, homens e mulheres, sobre o Parque do Guarapiranga, zona Sul da cidade de São Paulo, respondendo a pergunta: Como você descreveria este parque para alguém que nunca o visitou?

\begin{tabular}{|c|c|}
\hline HOMENS & MULHERES \\
\hline $\begin{array}{l}\text { É um lugar muito bom, bom para fazer exercício, é muito bom } \\
\text { para lazer }\end{array}$ & $\begin{array}{l}\text { Eu gosto do parque, não tenho muito que reclamar, falaria } \\
\text { que é bom, foi aqui que conheci meu marido }\end{array}$ \\
\hline $\begin{array}{l}\text { É um local adequado para visitar em um final de semana, fazer } \\
\text { um churrasco, praticar esportes, antigamente podia nadar na } \\
\text { represa }\end{array}$ & $\begin{array}{l}\text { Eu falaria que traz lazer e segurança, para adultos e crianças } \\
\text { e a paisagem boa, dá para ver a represa. }\end{array}$ \\
\hline É um parque que dá para fazer caminhada, refletir sobre a vida & $\begin{array}{l}\text { Que vale a pena vir conhecer, que é um lugar gostoso, se } \\
\text { você não tem nada para faze venha aqui, vem fazer um } \\
\text { piquenique, mas cuidado com as pessoas estranhas. }\end{array}$ \\
\hline É um lugar que dá para se aproximar da natureza e se ter lazer & Vim só por curiosidade, não tenho o que falar. \\
\hline $\begin{array}{l}\text { Que é bom, ótimo, vem gente de longe para cá, tem umas } \\
\text { churrasqueiras, dá para fazer um piquenique, descansa a } \\
\text { mente, }\end{array}$ & $\begin{array}{l}\text { Falaria muito bem, parque maravilhoso, limpinho, tem muita } \\
\text { gente que não sabe aproveitar, moro há } 14 \text { anos aqui, mas } \\
\text { frequento apenas } 2 \text { anos }\end{array}$ \\
\hline $\begin{array}{l}\text { Falaria que é bom, muito bom, apesar de que eu moro aqui a } \\
28 \text { anos, sempre vinha para cá, arrumei namorada aqui, é bom } \\
\text { para descansar a cabeça }\end{array}$ & $\begin{array}{l}\text { É um parque amplo, mas não tem infraestrutura, não voltaria } \\
\text { ao parque. }\end{array}$ \\
\hline $\begin{array}{l}\text { Esse parque é ótimo, eu recomendo para os amigos, sempre } \\
\text { frequentei aqui, O lbirapuera é bom, mas esse para descansar é } \\
\text { bom, para passear e vir com a família. Agora ele é bom, mas } \\
\text { tempos atrás era péssimo, tinha muito roubo, não tinha } \\
\text { segurança. }\end{array}$ & $\begin{array}{l}\text { É um parque bacana, bom, recomendaria, porque na } \\
\text { periferia não tem muito acesso... Passear conhecer a } \\
\text { natureza, tomar um ar puro, natureza boa e preservação boa }\end{array}$ \\
\hline $\begin{array}{l}\text { É um lugar agradável para caminhada, e para trazer crianças é } \\
\text { legal. }\end{array}$ & $\begin{array}{l}\text { Entre o Ibirapuera e outros parques, o Guarapiranga é o } \\
\text { melhor }\end{array}$ \\
\hline É um bom parque para passear & O parque é um ambiente natural agradável. \\
\hline $\begin{array}{l}\text { Ambiente bem familiar vale a pena para um fim de semana, } \\
\text { bom para fazer um churrasco. }\end{array}$ & $\begin{array}{l}\text { É um ótimo área de preservação, que pode ser utilizada para } \\
\text { vários fins, de estudo a lazer, é bom que os munícipes usem } \\
\text { o espaço público assim inibe que pessoas usem o parque de } \\
\text { forma inadequada, por exemplo usando maconha. }\end{array}$ \\
\hline É bom para ir a um fim de semana para passear. & $\begin{array}{l}\text { O parque é muito bom, a gente se sente bem, às vezes quer } \\
\text { ficar sozinha para pensar e a natureza ajuda muito. }\end{array}$ \\
\hline É bom para fazer caminhada pé ter o contato com a natureza. & $\begin{array}{l}\text { É um lugar agradável de ficar, pé bom para curtir os filhos e } \\
\text { conhecer novos amigos. }\end{array}$ \\
\hline $\begin{array}{l}\text { É um lugar bom para fazer esportes, namorar, curtir com os } \\
\text { amigos. }\end{array}$ & $\begin{array}{l}\text { O parque é bom para ter contato com a natureza e se sentir } \\
\text { bem. }\end{array}$ \\
\hline Não conheço bem. & É um lugar bom a tarde. \\
\hline $\begin{array}{l}\text { Uma reserva ecológica dentro da cidade, com uma variedade } \\
\text { de espécies vegetais e com uma ótima visão da represa do } \\
\text { Guarapiranga }\end{array}$ & $\begin{array}{l}\text { É um parque que você pode se divertir, ter contato com a } \\
\text { natureza e passear com a família. }\end{array}$ \\
\hline
\end{tabular}

Elaborado pelos autores 
Nas respostas dos frequentadores entrevistados do Parque do Guarapiranga observa-se que a palavra "área verde" diversas vezes, o que evidencia que o parque é um local reconhecido como um ambiente em que a pessoa se sente mais próxima a um ambiente natural.

Outra palavra que aparece em vários depoimentos é 'ambiente familiar', isto demonstra o uso do parque para encontro sociais e familiares, observou-se que há no parque áreas que colaboram para o convívio social, como parque para crianças e churrasqueiras. Entretanto, o fator considerado mais preocupante pelos frequentadores em seus comentários foi a segurança, sendo citado por um deles como o uso inadequado por 'maconheiros'.

No quadro 1 , foi observado nas respostas dos entrevistados que homens e mulheres tem opiniões distintas em relação ao parque, as mulheres foram mais críticas em relação a aspectos que devem ser melhorados no parque, Tais resultados são semelhantes aos obtidos por Régis (2015), em seu estudo realizado no Parque da Água Branca/SP.

Os comentários reforçam a ideia que a tomada de consciência pelo indivíduo do ambiente é definida pela percepção que se tem do lugar em que este se encontra, segundo Tuan (2012) a percepção ambiental, é de forma geral, a resposta dos sentidos aos estímulos externos que guarda relação com o contexto sociocultural do indivíduo.

Os comentários feitos tanto por homens como pelas mulheres apontam conhecimento sobre os serviços que o parque pode proporcionar ao ambiente, com frases como ' respirar um ar puro', '... é uma reserva ecológica dentro da cidade', o que também foi observado nos estudo de Jim \& Chen (2006).

A percepção ambiental é uma importante ferramenta e pode orientar a formulação de políticas públicas ajustadas às necessidades e ansiedades que as pessoas têm em relação ao espaço em que estão inseridos.

Podemos observar em grande parte dos comentários a presença de adjetivos como agradável, bom, importante, tranquilo, familiar, assim como frases com ' bom para passear', ' ambiente familiar', ' que eu amo' demonstram um parecer favorável em relação ao parque.

Observa-se nas respostas a percepção que os frequentadores têm pelo parque, o carinho e os cuidados na sua conservação, permite concluir que o parque com sua infraestrutura e áreas verdes cumpre a função de proporcionar lazer, recreação, descanso físico e mental e atende as expectativas da maioria de seus frequentadores.

Resultados parecidos foram observados em estudo do Parque Ecológico do Tiete por Teramussi (2008), segundo a autora cada indivíduo percebe, reage e responde diferentemente às ações sobre o ambiente em que vive. As respostas ou manifestações daí decorrentes são resultado das percepções (individuais e coletivas), dos processos cognitivos, julgamentos e expectativas de cada pessoa.

Observação realizada no parque indicaram que a infraestrutura para pessoas com mobilidades reduzida do parque necessita ser melhorada, cadeirantes tem dificuldade para se locomover, assim como gestantes e idosos, pois as principais ruas apresentam declividade acentuada e são pavimentadas com paralelepípedos o que aumenta o perigo de quedas e impossibilita a locomoção de cadeiras de rodas. 


\section{CONCLUSÕES}

A análise dos resultados destaca a importância que o parque tem para os frequentadores entrevistados, pois demonstram em suas respostas a satisfação de estar nele e seu valor enquanto espaço de interação com a natureza e social.

Algumas respostas como - '...um parque com playground para as crianças, um bom lugar para passar o dia com as crianças...' ou '...um parque bastante familiar...' indicam ser para eles um espaço de convívio familiar e social, sua infraestrutura contribui pela presença de quiosques, churrasqueiras, quadras poliesportivas e playgrounds. Contribui também o convívio de frequentadores de várias faixas etárias, em razão de oferecer espaços de parquinho para as crianças, de caminhadas para um público mais adulto e aparelhos de longevidade para os mais idosos.

A presença do Centro de Convivência e Cooperativa (CECCO) da secretaria municipal de Saúde e do Bosque da leitura pela secretaria municipal de Cultura contribui para que o parque desenvolva atividades diferenciadas proporcionando várias opções de lazer e cultura para os frequentadores do parque.

Observa-se, pela frequência das respostas onde as palavras área verde, ser está um grande atrativo para as pessoas. As frases '...reserva ecológica, dentro da cidade...', '...é um ambiente natural...', indica a percepção de quanto o parque traz de benefício as pessoas pela aproximação com a natureza, outras frases como '... as vezes a gente quer ficar sozinha para pensar a natureza...' ou '... ganharia com a qualidade de vida, o rompimento com a agressão (visual) que a gente sofre todo dia, indicam que a percepção de que o contato com a natureza traz benefícios a saúde emocional e psicológica, o que reafirma estudos como o de Chiesura (2004) que diz 'Os parques urbanos fornecem benefícios ambientais e ecológicos, sociais e psicológicos importantes para as sociedades humanas enriquecendo a vida humana com significados e emoções'.

O Parque Guarapiranga é uma grande área verde localizada em uma região de grande adensamento populacional, segundo dados da prefeitura de São Paulo a região controlada pela subprefeitura de M'Boi Mirim possuía em 2010 uma população de 563.305 pessoas com uma densidade populacional de 9.071 habitantes/km2, ganhando, importância ecológica e social. Apesar de localizado em área de proteção de mananciais a pressão da população por moradia e a ação de grupo de especuladores imobiliários torna sua presença e manutenção crucial para desenvolvimento sustentável da região.

A infraestrutura para pessoas com mobilidades reduzida como cadeirantes, gestantes e idosos necessita ser melhorada, os trabalhos desenvolvidos pelo CECCO e a instalação de equipamentos de ginástica ao ar livre que servem a estas pessoas, porém grande parte da área do parque permanece inacessível, não há também preocupação com as pessoas com deficiência visual, não foram encontrados nenhuma guia nas ruas para cegos ou placas em braile. 


\section{REFERENCIAS}

BARBEDO, Adeliana SC et al. Manual técnico de arborização urbana.Secretaria Municipal do Verde e do Meio Ambiente, p. 45, 2005.

BAHLS, Aparecida Vaz da Silva. O verde na metrópole: a evolução das praças e jardins em Curitiba (1885-1916). 1998. Tese de Doutorado. Universidade Federal do Paraná.

BARTALINI, Vladimir. Parques Públicos Municipais de São Paulo. A ação da municipalidade no provimento de áreas verdes de recreação. 1999. 302f. Dissertação (Doutorado em Arquitetura) Faculdade de Arquitetura e Urbanismo, Universidade de São Paulo, São Paulo.

CHAKARIAN, Luciana. Uso e ocupação do solo urbano em encostas na área de proteção de mananciais da Bacia de Guarapiranga. 2008. Tese de Doutorado. Universidade de São Paulo.

CHIESURA, Anna. The role of urban parks for the sustainable city.Landscape and urban planning, v. 68 , n. 1, p. 129-138, 2004.

FERNANDES, Roosevelt $S$. et al. Uso da percepção ambiental como instrumento de gestão em aplicações ligadas às áreas educacional, social e ambiental. Encontro nacional de pós-graduação e pesquisa em ambiente e sociedade, v. 2, p. 1-15, 2004.

GARCIA, Ricardo J. Francischetti; PIRANI, Jose Rubens. Estudo florístico dos componentes arbóreo e arbustivo da mata do Parque Santo Dias, São Paulo, SP, Brasil. Boletim de Botânica da Universidade de São Paulo, p. 15-42, 2001.

GOMES, Marcos Antonio Silvestre; SOARES, Beatriz Ribeiro. A vegetação nos centros urbanos: considerações sobre os espaços verdes em cidades médias brasileiras. Estudos Geográficos, v. 1, n. 1, p. 29-39, 2003.

GPMSP - Guia dos Parques Municipais de São Paulo, 3 Edição Atualizada e Revisada. Disponível em < http://www.prefeitura.sp.gov.br/cidade/secretarias/upload/meio_ambiente/ arquivos/publicacoes/guia_dos_parques_3.pdf >. Acesso em 24, Setembro, 2015.

BRASIL, I. B. G. E. Instituto Brasileiro de geografia e Estatística. Censo Demográfico 2010, 2010. Disponível em < http://www.censo2010.ibge.gov.br/sinopse/index.php?uf=35\&dados=0>. Acesso em 24, dezembro, 2015.

JIM, C. Y.; CHEN, Wendy Y. Perception and attitude of residents toward urban green spaces in Guangzhou (China). Environmental management, v. 38, n. 3, p. 338-349, 2006.

RÉGIS, Milena de Moura. 2016. Percepção ambiental e uso de Parques Urbanos por frequentadores do Parque Jardim da Conquista, São Paulo/SP. Tese (Doutorado em Gestão e Sustentabilidade) - 


\section{ANAP

Universidade Nove de Julho - UNINOVE, São Paulo.

RODRIGUES, Mariana Lima et al. A percepção ambiental como instrumento de apoio na gestão e na formulação de políticas públicas ambientais. Saúde e Sociedade, v. 21, n. suppl. 3, p. 96-110, 2012.

SILVA, Angélica dos Santos da.et al.. Percepção Ambiental De Frequentadores E Estudo Dos Impactos Do Parque Ecológico Laguna da Jansen, Município De São Luís, MA. In Congresso Brasileiro de Gestão Ambiental, v.3, 2012.

SVMA - Secretaria do Verde e do Meio Ambiente. Disponível em < http://www.prefeitura.sp.gov.br/cidade/secretarias/meio ambiente/parques/index.php?p=49467 > Recuperado em 25, Setembro, 2015.

TERAMUSSI, Thais Moreto. Percepção ambiental de estudantes sobre o Parque Ecológico do Tietê, São Paulo-SP. 2008. Tese de Doutorado. Universidade de São Paulo.

TUAN, Yi-Fu. Topofilia: um estudo da Percepção. Atitudes e Valores do Meio, 1980. DIFEL, Espaço e lugar: a perspectiva da experiência. São Paulo: DIFEL.

VERGARA, Sylvia Constant. Métodos de Coleta de Dados no Campo. Editora Atlas. 2012. São Paulo

VERGARA, Sylvia Constant. Projetos e Relatórios de Pesquisa em Administração. Editora Atlas. 2000. São Paulo 